\title{
OSTEOMALACIA FOLLOWING GASTRECTOMY
}

\author{
By Philip Ellman, M.D., F.R.C.P., and D. B. IRwiN, M.D., M.R.C.P.* \\ From the Department of Medicine, Dorking General Hospital, Surrey
}

\section{Introduction}

Gastrectomy is a common operation and its complications and sequelae have been extensively studied. Brain and Stammers (195I) consider that loss of weight and steatorrhoea commonly occur after even partial gastrectomy. Brain (1953) thought that the steatorrhoea, which was usually mild, was due to an upset of pancreatico-biliary secretion and gastro-duodenal mechanism, allowing food to pass through the upper intestinal tract before these mechanisms came fully into action. He recommended a diet with a high fat content divided into numerous meals throughout the day.

Osteomalacia due to steatorrhoea is well known and it is surprising that this condition following gastrectomy has so rarely been reported. Sarasin (194I) reported two cases, both female, who underwent partial gastrectomy for benign gastric ulcer. Symptoms due to osteomalacia developed 12 and 20 years later, at the ages of 59 and 60 years. Both had steatorrhoea and microcytic anaemia and improved on treatment with calcium, vitamin D, and iron. Pyrah and Smith (1956) report the case of a female, aged 52 , where pain due to osteomalacia developed seven years after partial gastrectomy for benign gastric ulcer. She was found to have steatorrhoea and was treated for a severe microcytic anaemia. Radiology showed multiple spontaneous fractures including 15 ribs and all four pelvic rami. She recovered with calcium and vitamin $\mathrm{D}$ therapy. They also quote Groult (1945), who described the case of a nun, aged 42 , in whom extensive bone changes were found 17 years after gastrectomy. The response to calcium, calciferol and ultra-violet irradiation was good. Hartley (1957) described a case of probable osteomalacia in a man, aged 63 , developing two years after gastrectomy. His fat metabolism was not studied but he was considered to be a case of osteomalacia due to steatorrhoea following gastrectomy.

In view of the apparent rarity of this sequel to gastrectomy we report the following case:

*Now at the Royal Salop Infirmary, Shrewsbury.

\section{Case Report}

V.H., a retired nurse, aged 63 , began in 1941 , whilst still nursing, to experience epigastric pain with vomiting. This was demonstrated on several occasions to be due to a gastric ulcer. Her digestive symptoms became worse following a vaginal hysterectomy for retroversion and in 1948 she had a haematemesis and melaena. Investigations, including gastroscopy, showed a large gastric ulcer. In March 1949 partial gastrectomy with retrocolic proximal loop to lesser curve Polya operation was performed. Histological examination confirmed the diagnosis and no evidence of malignancy was seen. Her post-operative course was complicated by the vomiting of bile for about ro weeks, bug after that she became well, her ulcer symptoms disappeared and she regained some of her los weight. It was found necessary, however, to treat her for anaemia with a single course of liver injections.

She remained in normal health until January 1956, when, quite suddenly, she developed weakness and pain in the thighs. Later this spread to her lower back ribs and arms. These pains were especially troublesome at night and on turning over in bed. Her weakness was so marked that it was difficult for her to lift her foot on to a stool or to raise her arm to pull down a blind. It would take her about 25 minutes to get out of bed and walk to the bathroom. She fell on one occasion and a chest X-ray in 1956 showed a fracture of the right 8th rib.

In August 1956 her general practitioner referred her to an orthopaedic surgeon. Examination disclosed tenderness of the back muscles and rigidity of the spine, and X-rays were reported as showing 'osteoporosis' of the spine and narrowing of the disc space between $\mathrm{C}_{5}$ and $\mathrm{C6}$. Her haemoglobin was 75 per cent. and red blood cells were $4,110,000$ per c.mm., with a normal differential count. The plasma uric acid was $3.5 \mathrm{mg}$. per $100 \mathrm{ml}$. She was treated with liver and fitted with a spinal support.

Her symptoms persisted and, on January 10, 1957, she was admitted to the medical unit under 
the care of one of us (P.E.), where a diagnosis of osteomalacia and malabsorption syndrome was made.

\section{Clinical Examination}

A thin, ill-looking woman.

\section{Cardio-vascular System}

Pale but not anaemic clinically. No cyanosis or jaundice. Blood pressure 130/80. Apex beat in $5^{\text {th }}$ intercostal space 3 in. from midline, impulse easily palpable and of normal character. Heart not enlarged clinically. Heart sounds normal with no murmurs. Fundi showed grade I changes. No signs of congestive heart failure but there was slight pitting oedema of the ankles. Dorsalis pedis both palpable.

\section{Respiratory System}

Trachea central. No clubbing. Chest movement symmetrical. No abnormality was detected either clinically or radiologically.

\section{Alimentary System}

Tongue clean and moist. Teeth all artificial. Throat clear. Abdomen showed little adipose tissue, old, well-healed supra-umbilical and right inguinal scars. No abnormal pulsations or visible peristalsis. No tenderness or guarding. Liver, spleen and kidneys not felt. No masses.

\section{Central Nervous System}

Cranial nerves showed no abnormalities. No motor, sensory or reflex changes. Plantar responses were flexor.

\section{Skeletal System}

Crown to pubis $29 \frac{1}{2}$ in., pubis to heel $3 \mathrm{I}$ in., span $6_{5}$ in., height $62 \frac{1}{4}$ in. There was pain on movement and tenderness of the chest wall on pressure. The range of movement of all joints was full.

\section{Endocrine System}

Some loss of hair from scalp. Eyebrows normal. Skin not abnormally dry. Thyroid not enlarged. No signs of thyrotoxicosis. No abnormal pigmentation. No corneal calcification. Chvostek and Trousseau signs negative.

\section{Investigations}

Haemoglobin 80 per cent., red blood cells $3,830,000$ c.mm. with normal white and differential cell counts. E.S.R. (Westergren) $6 \mathrm{~mm}$. in one hour. Serum cholesterol, plasma proteins (total and differential), routine examination of a catheter specimen of urine, serum urea, urea clearance test and basal metabolic rate were all normal. Serum alkaline phosphatase examinations, before treatment, gave results of $12.3,20.4,14.3$ and 22.4 King Armstrong units on different days. Serum acid phosphatase results were normal. Serum calcium estimations were $10.3,8.7$ and 8.9 per $100 \mathrm{ml}$. Fat-balance studies could not be carried out at this time, but estimations of the faecal fat content of dried stool showed $23.4 \mathrm{~g}$. and 22.4 g. per $100 \mathrm{~g}$., with 80 per cent. split fat. During a later admission, in August 1957, faecal fat estimations showed $28.6 \mathrm{~g}$. and $32.4 \mathrm{~g}$. per I00 g. of dried faeces. The urinary calcium excretion on a normal diet (calcium content unknown) was $23.6 \mathrm{mg}$. in 24 hours. An oral glucose-tolerance test showed a lag storage type of curve, fasting blood sugar $104 \mathrm{mg}$. per $100 \mathrm{ml}$., and at 30-minute intervals after ingestion of $50 \mathrm{~g}$. glucose, 250, 162, 80, 62, 80 and $66 \mathrm{mg}$. per $100 \mathrm{ml}$. with a trace of sugar in the urine at one and two hours. An intravenous glucose-tolerance test showed a fasting blood sugar of $102 \mathrm{mg}$. per $100 \mathrm{ml}$., and at 30-minute intervals, 300, 244, 162, I 16 and $94 \mathrm{mg}$. per $100 \mathrm{ml}$. A fractional test meal showed achlorhydria, but histamine was not given. Meat fibres were not found in the stools. A vitamin A absorption test showed a rise from 116 to 3070 I units in four hours.

\section{Radiology}

In August $1956 \mathrm{X}$-rays of the pelvis showed a fracture of the left inferior pubic ramus, without displacement and with little obvious callus formation. The bones appeared otherwise normal. In January 1957 there was no change in this fracture but a ribbon-like fracture had appeared in the left superior pubic ramus, again without displacement or callus. X-rays of the chest in August $195^{6}$ showed a fracture of the right 8th rib with some callus formation but no displacement. In January 1957 similar fractures were visible in the right 7 th, 8th and 9th ribs, and the left 8th and 9th ribs.

After treatment, films in July 1957 showed that all these fractures had healed well, and there was a healed fracture in the left 7 th rib, not previously visible. Barium meal and follow-through showed some evidence of diverticulosis but none of steatorrhoea.

\section{Progress and Treatment}

While investigation proceeded she was treated symptomatically with soluble aspirin and gastric regime. On February 16, 1957, oral calcium gluconate $40 \mathrm{gr}$. daily, and capsules containing a daily dose of vitamin A 54,000 units and vitamin D I I,000 units were started. Treatment was continued at this level for five months and the vitamins were then reduced by half. Within one month of starting treatment her pains were much less, and 
by the end of six weeks she was pain-free and felt stronger. Investigations on April 8, 1957, showed serum alkaline phosphatase 37 King Armstrong units, serum calcium $9.8 \mathrm{mg}$. per $100 \mathrm{ml}$. and serum inorganic phosphate $4 \mathrm{mg}$. per $100 \mathrm{ml}$. The high alkaline phosphatase was explained by the active repair process. In September 1957 the serum alkaline phosphatase was $8,8.8$ and 10 King Armstrong units, the serum calcium 9.7, 9.5 and $9.2 \mathrm{mg}$. per $100 \mathrm{ml}$. , and the serum inorganic phosphate 5.5 and $3.1 \mathrm{mg}$. per $100 \mathrm{ml}$. The 24hour urinary calcium excretion was $187 \mathrm{mg}$. Treatment with iron resulted in her haemoglobin rising to 95 per cent. Her fat intake was increased and frequent meals were given. There was no diarrhoea.

In view of the lack of conclusive evidence of steatorrhoea, she was referred to Professor Dent's Unit at University College Hospital for fat balance studies in August 1958. The result of a six-day fat balance showed 84.I per cent. absorption on an intake of $36 \mathrm{~g}$. per day. A vitamin A absorption test showed a plasma level of 62 units, rising after four hours to 960 i.u. per $100 \mathrm{ml}$. X-rays of the abbreviated skeleton showed slight decalcification, with old fractures in the 8th right and 7 th, 8th and gth left ribs, and an old healed fracture of the left inferior pubic ramus. There were no signs suggesting hyperparathyroidism. Total 24-hour urinary calcium excretion was $8 \mathrm{mg}$.

\section{Discussion}

It is now well recognized that osteomalacia is, in this country at least, only very rarely due to the classical cause of lack of dietary vitamin D. Nevertheless, such cases continue to be seen occasionally when patients, who have unusual food fads, choose abnormal diets (Dent, 1957). In the case described here there were no such food fads and it can be clearly stated that there could have been no lack of vitamin $\mathrm{D}$ in the diet following operation. More commonly, at the present time in this country, osteomalacia is due to renal failure, renal tubular disturbances, or to hereditary causes (Dent and Harris, 1956), or to steatorrhoea as pointed out by Parsons (1927) and Bennett and others (1932). Which of these causes might be operative in our case was not obvious from the clinical history, although the history of partial gastrectomy some years earlier did suggest that steatorrhoea might be the precipitating cause, even though such steatorrhoea must have been occult. The investigations were at first not much more rewarding, since a first vitamin $A$ absorption test was normal, and the figures of faecal fat content were not pathognomonic of steatorrhoea. It was even suggested that she might have post-gastrectomy osteomalacia without steatorrhoea, as has been seen by Dent and Rose (personal communica- ̊̊ tion). It was felt necessary to decide definitely whether or not steatorrhoea was present, and a fat $\stackrel{D}{2}$ balance was therefore carried out in Professor C. E. $c$ Dent's department and this revealed definite $\overrightarrow{\vec{F}}$ evidence of steatorrhoea.

This case, therefore, is similar to that reported by Pyrah and Smith (1956) and most others, and it is noteworthy that they have followed the Polya type of partial gastrectomy. In the reported cases, including the present one, the ages at $\mathrm{w}$ diagnosis were $59,60,52,42$ and 63 years and the onset of pains due to bone disease occurred 12, 20, $\overrightarrow{\vec{\omega}}$ 7,17 and 7 years after partial gastrectomy. The possible case aged 63 reported by Hartley (1957) occurred two years after operation and was the 3 only male case. The results of treatment with calcium and vitamin $\mathrm{D}$ have been good, pain and weakness disappearing in four to six weeks, and fractures healing quickly.

Rose (1957) stated that the precise time relationship between the onset of steatorrhoea and of $\frac{9}{2}$ osteomalacia was not clear but he felt that the intervals might be from three to ten years. The onset might be fairly sudden or insidious, and the $\overparen{D}$ steatorrhoea might be overt or occult. If the $\vec{\theta}$ osteomalacia were of relatively sudden onset might be characterized by the development of. Looser's nodes. Dent and Hodson (1954) cons sidered that these occur in any relatively acute osteomalacia.

Since gastrectomy followed by steatorrhoea is a relatively common condition, it may be that osteomalacia of this type is not as rare as might appear from the paucity of the diagnoses. The symptoms of limb pain and weakness, first beginning in the lower part of the body and later between the joints and not in the joints, may be widespread and vague without definite abnormal physical signs and may be thought to be neurotic in origin, rather than due to metabolic bone disease, and steatorrhoea may not be clinically obvious. The long latent period between operation and the onset of symptoms is also likely to cause difficulty. As the condition causes considerable disability but responds well to treatment, correct diagnosis is important and increased awareness of the condition may lead to $\sigma$ further cases being found. Correct treatment is $N$ most rewarding, as in the patient described here. It is perhaps worth stressing, however, that only moderate doses of vitamin $\mathbf{D}$ appear to be necessary in the treatment of post-gastrectomy steatorrhoea.

The sex ratio is interesting and it would be tempting to suggest that this is a factor in causation, but sufficient cases have not yet been studied to decide the true incidence. 


\section{Summary}

A case of osteomalacia due to steatorrhoea following partial gastrectomy is described. Attention is drawn to the rarity of reports of this condition, and to the possibility that it may be overlooked. Possible reasons for this are advanced. Five out of the six cases so far reported were female and in five out of six cases symptoms developed from 7 to 20 years after operation. The condition causes considerable disability and responds well to treatment with calcium and vitamin D. Further studies are needed to determine its incidence and the important factors concerned in its causation.

\section{Acknowledgments}

We wish to express our thanks to Professor
C. E. Dent and Dr. G. A. Rose for their valuable help with the fat balance studies and other investigations.

\section{BIBLIOGRAPHY}

BENNETT, T. I., HUNTER, D., and VAUGHAN, J. M. (1932), Quart. f. Med., 1,603 .

BRAIN, R. H. F. (I953), Proc. R. Soc. Med., 46, 438.

BRAIN, R. H. F., and STAMMERS, F. A. R. (I95I), Lancet, is II37.

DENT, C. E., and HODSON, C. J. (1954), Brit. F. Radiol., 27, 605. DENT, C. E. (1957), Proc. R. Soc. Med., 50, 383.

DENT, C. E., and HARRIS, H. (1956), f. Bone F. Surg., 38b, 204. GROULT, P. (1945), Arch. Med. le'g. Med. Soc. Lille, I, 55.

HARTLEY, J. (1957), F. Mt. Sinai Hosp., 24, 346.

PARSONS, L. G. (1927), Arch. Dis. Childh., 2, 198.

PYRAH, L. N., and SMITH, I. B. (1956), Lancet, i, 935.

ROSE, G. A. (1957), Proc. R. Soc. Med., 50, 371.

SARASIN, C. (I94I), Gastroenterologie, 66, 182.

\section{THYROID DISEASE}

Price: 4s. 0d., post free

\section{DIAGNOSTIC PROCEDURES IN THYROID DISEASE}

Russell Fraser, M.D., F.R.C.P., D.P.M.

THE PLACE OF RADIOACTIVE IODINE IN THE TREATMENT OF THYROID DISEASE

E. E. Pochin, M.D., F.R.C.P.

\section{ANTITHYROID DRUGS}

James Crooks, M.B., M.R.C.P. (Lond. and Ed.), F.R.F.P.S.G.

\section{SUBACUTE THYROIDITIS}

Selwyn Taylor, M.Ch., F.R.C.S.
RECENT WORK ON THYROID HORMONES

J. H. Wilkinson, B.Sc., Ph.D., F.R.I.C.

SOME UNUSUAL MANIFESTATIONS OF THYROID DISEASE

W. R. Trotter, D.M., M.R.C.P.

CARCINOMA OF THE THYROID

John E. Piercy, F.R.C.S., F.R.C.S.E.

LYMPHOID GOITRES

T. Levitt, M.A., F.R.C.S.Eng., F.R.C.S.Ed., F.R.C.S.I.

Published by

\section{THE FELLOWSHIP OF POSTGRADUATE MEDICINE}

